\title{
Relationship between intestinal flora and inflammatory factors in patients with nonalcoholic steatohepatitis
}

\author{
JIAN ZHANG, CHUNYING WANG, JI WANG and FENGCHI ZHANG \\ Department of Liver Disease, Xuzhou Infectious Disease Hospital, Xuzhou, Jiangsu 221000, P.R. China
}

Received May 23, 2017; Accepted September 12, 2017

DOI: $10.3892 / \mathrm{etm} .2017 .5490$

\begin{abstract}
This study was conducted to analyze the change in intestinal flora of patients with nonalcoholic steatohepatitis and its correlation to the levels of the inflammatory cytokines interleukin-10 (IL-10) and IL-17. We selected 90 patients that were diagnosed with and treated for nonalcoholic steatohepatitis as the patient group and 80 healthy cases as the control group. We then compared the intestinal flora in the subject feces and the intestinal colonization resistance (B/E, Bifidobacterium to Enterobacter) of both groups. Using RT-PCR, we also detected IL-10 and IL-17 mRNA levels in the peripheral blood mononuclear cells of both groups. Furthermore, we used the ELISA method to determine serum IL-10 and IL-17 levels in order to explore the correlation between IL-10, IL-17 and B/E. The number of Bifidobacterium and Lactobacillus were significantly lower in the patient group than the control group $(\mathrm{P}<0.05)$, while Enterobacter and Enterococcus pathogenic bacteria were significantly higher in the patient group than the control group $(\mathrm{P}<0.05)$. The $\mathrm{B} / \mathrm{E}$ value was lower in the patient group than the control group $(\mathrm{P}<0.05)$. The relative expression of IL-10 and IL-17 mRNA in the patient group was significantly higher than in the control group $(\mathrm{P}<0.05)$. In the patient group, the serum IL-10 levels were $1.17 \pm 0.15 \mathrm{pg} / \mathrm{ml}$, which is significantly higher than the control group serum IL-10 levels which were $0.32 \pm 0.04 \mathrm{pg} / \mathrm{ml}(\mathrm{P}<0.05)$. The serum IL-17 levels in the patient groups were $0.96 \pm 0.11 \mathrm{pg} / \mathrm{ml}$, which was significantly higher than the control group, which had an average of $0.28 \pm 0.01 \mathrm{pg} / \mathrm{ml}$ serum IL-17 levels $(\mathrm{P}<0.05)$. Pearson's correlation analysis showed that the change of $\mathrm{B} / \mathrm{E}$ value of intestinal flora in the patients group were negatively correlated with serum IL-10 ( $\mathrm{r}=-0.546, \mathrm{P}<0.05)$, and negatively correlated with serum IL-17 $(\mathrm{r}=-0.535, \mathrm{P}<0.05)$. Therefore,
\end{abstract}

Correspondence to: Dr Fengchi Zhang, Department of Liver Disease, Xuzhou Infectious Disease Hospital, 300 Shuangyong Road, Xuzhou, Jiangsu 221000, P.R. China

E-mail: fengchizhang1630@163.com

Key words: nonalcoholic steatohepatitis, inflammatory factor, intestinal flora, IL-10, IL-17 compared to healthy people, the expression of IL-10 and IL-17 in the peripheral blood of patients with non-alcoholic fatty liver is high. The changes in intestinal flora in patients with nonalcoholic steatohepatitis are closely related to the changes of serum IL-10 and IL-17 levels, and they are involved in the development of nonalcoholic steatohepatitis.

\section{Introduction}

Nonalcoholic fatty liver disease is a type of common chronic liver disease, with a gradually increasing number of cases in China. This disease threatens people's physical and mental health (1). The pathogenesis of nonalcoholic fatty liver disease remains unclear, and most studies suggest that (2-4) this disease may be closely related to many factors such as abnormal lipid metabolism and an inflammatory response. Nonalcoholic steatohepatitis is an important stage during the development and progression of nonalcoholic fatty liver disease. In recent years, many studies have demonstrated that the imbalance of intestinal flora in the body leads to obesity, which is closely related to nonalcoholic steatohepatitis (5). Interleukin-10 (IL-10) and IL-17 are relatively common pro-inflammatory factors. Currently, there are few studies on the correlation between changes in intestinal flora and the inflammatory factors IL-10 and IL-17 in patients with nonalcoholic steatohepatitis. Here we analyzed the correlation between changes in intestinal flora and IL-10 and IL-17 in order to reveal the pathogenesis of nonalcoholic fatty liver disease.

\section{Patients and methods}

General data. Ninety patients that were diagnosed with nonalcoholic steatohepatitis and treated at Xuzhou Infectious Disease Hospital from February 2016 to February 2017 were selected as the patient group. Their diagnosis conformed to the diagnostic criteria in Diagnosis and Treatment Guidance on Nonalcoholic Fatty Liver Disease (6). Patients with viral or autoimmune liver disease, pregnant or lactating patients, and patients with prior use of medicine that would affect the intestinal flora in the body in the prior 15 days were eliminated. In the patient group, there were 50 males and 40 females aged 25-66 years with an average age of $45.7 \pm 1.5$ years. In the control group, there were 80 healthy people without intestinal, hepatic and biliary diseases who were undergoing 
Table I. Comparison of intestinal flora amount and B/E value between the two groups $(\log \mathrm{CFU} / \mathrm{g})$.

\begin{tabular}{|c|c|c|c|c|c|c|}
\hline Groups & $\mathrm{n}$ & Bifidobacterium & Lactobacillus & Enterobacteriaceae & Enterococcus & $\mathrm{B} / \mathrm{E}$ value \\
\hline Patient & 90 & $8.56 \pm 0.34$ & $9.07 \pm 0.02$ & $9.88 \pm 0.42$ & $8.02 \pm 0.25$ & $0.87 \pm 0.03$ \\
\hline Control & 80 & $9.68 \pm 0.55$ & $9.84 \pm 0.36$ & $8.63 \pm 0.17$ & $7.35 \pm 0.14$ & $1.04 \pm 0.05$ \\
\hline t-test & & 9.561 & 10.942 & 7.338 & 8.796 & 9.005 \\
\hline P-value & & $<0.05$ & $<0.05$ & $<0.05$ & $<0.05$ & $<0.05$ \\
\hline
\end{tabular}

B/E, Bifidobacterium to Enterobacter.

physical examination in the hospital during the same time period and were selected as the control group, including 38 males and 32 females aged 24-65 years with an average age of $45.2 \pm 1.3$ years. All the patients and/or guardians signed the informed consent. The study was approved by the Ethics Committee of Xuzhou Infectious Disease Hospital.

\section{Methods}

Determination of intestinal flora. A total of $1.5 \mathrm{~g}$ of fresh excreta was collected from all subjects, and the log value of the colony forming unit in wet weight per gram of excreta (log $\mathrm{CFU} / \mathrm{g}$ ) was used for the viable count of intestinal beneficial bacteria, such as Bifidobacterium and Lactobacillus, and pathogenic bacteria, such as Enterobacter and Enterococcus. The ratio of Bifidobacterium to Enterobacter (B/E value) was calculated to indicate the index of intestinal colonization resistance, thus evaluating the changes in intestinal flora of subjects.

Determination of relative expression levels of IL-10 mRNA and IL-17 mRNA in peripheral blood mononuclear cells. A total of $5 \mathrm{ml}$ of fasting venous blood was collected from the subjects, and the changes in relative expression levels of IL-10 mRNA and IL-17 mRNA in the peripheral blood mononuclear cells were detected via reverse transcription-polymerase chain reaction (RT-PCR).

Determination of serum IL-10 and IL-17 levels. The serum IL-10 and IL-17 levels in subjects were detected via ELISA.

Statistical analysis. The SPSS 20.0 (IBM Corp., New York, NY, USA) statistical software was used for analysis. Measurement data were presented as mean \pm standard deviation, and the Chi-square test was used for measurement data. Paired samples t-test was used for enumeration data, and the Pearson's correlation analysis was used for the correlation analysis. $\mathrm{P}<0.05$ is considered to indicate a statistically significant difference.

\section{Results}

Comparisons of intestinal flora amount and $B / E$ value between the two groups. The number of beneficial bacteria, such as Bifidobacterium and Lactobacillus, in patient group was significantly lower than in the control group $(\mathrm{P}<0.05)$. The number of pathogenic bacteria, such as Enterobacteriaceae and Enterococcus, in the patient group was significantly higher than that in the control group $(\mathrm{P}<0.05)$, and the $\mathrm{B} / \mathrm{E}$ value in the patient group was significantly lower than in the control group $(\mathrm{P}<0.05)($ Table I).
Table II. Comparisons of relative expression levels of IL-10 mRNA and IL-17 mRNA between the two groups (mean \pm standard deviation).

\begin{tabular}{lccc}
\hline Groups & $\mathrm{n}$ & $\mathrm{IL}-10 \mathrm{mRNA}$ & $\mathrm{IL}-17 \mathrm{mRNA}$ \\
\hline Patient & 90 & $0.67 \pm 0.06$ & $0.62 \pm 0.04$ \\
Control & 80 & $0.18 \pm 0.03$ & $0.16 \pm 0.02$ \\
t-test & & 9.116 & 9.832 \\
P-value & & $<0.05$ & $<0.05$ \\
\hline
\end{tabular}

IL, interleukin.

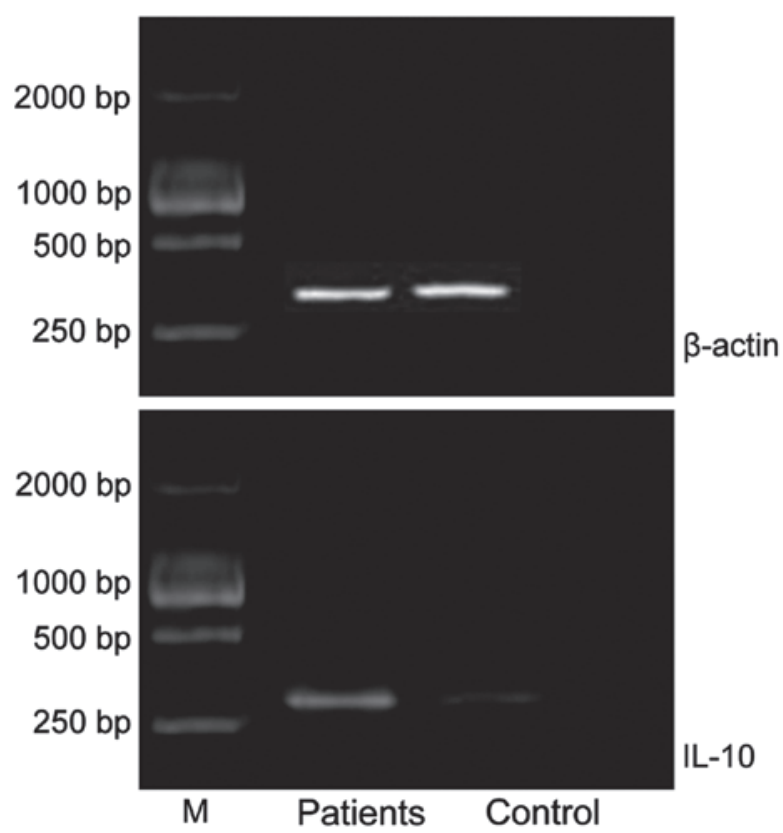

Figure 1. IL-10 mRNA expression in peripheral blood mononuclear cells. M, marker; IL, interleukin.

Comparisons of relative expression levels of $I L-10 \mathrm{mRNA}$ and $I L-17$ mRNA between the two groups. The relative expression levels of IL-10 mRNA and IL-17 mRNA in the patient groups were significantly higher than those in control group $(\mathrm{P}<0.05)$ (Table II; Figs. 1 and 2).

Comparison of serum IL-10 and IL-17 levels between the two groups. The serum IL-10 levels in the patients group 


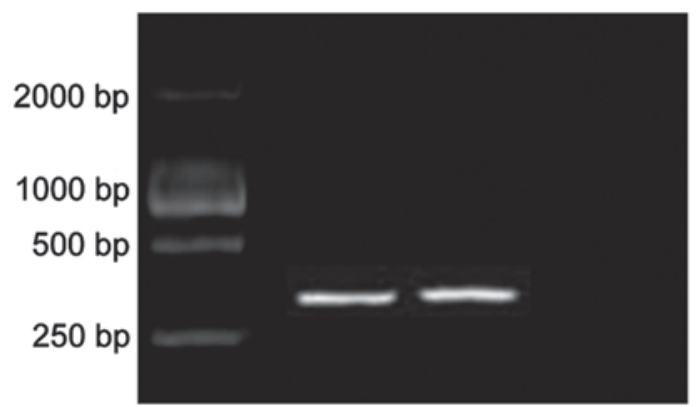

$\beta$-actin

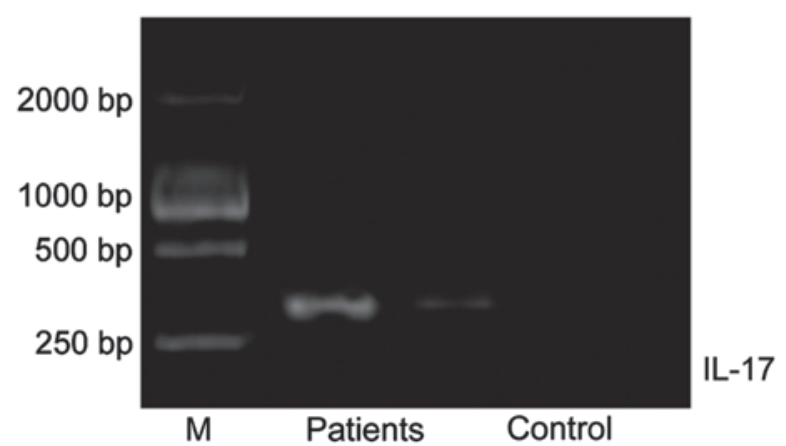

Figure 2. IL-17 mRNA expression in peripheral blood mononuclear cells. M, marker; IL, interleukin.

were $1.17 \pm 0.15 \mathrm{pg} / \mathrm{ml}$, which was significantly higher than that in control group at $0.32 \pm 0.04 \mathrm{pg} / \mathrm{ml}(\mathrm{P}<0.05)$. The serum IL-17 level in the patient group was $0.96 \pm 0.11 \mathrm{pg} / \mathrm{ml}$, which was significantly higher than that in the control group $(0.28 \pm 0.01 \mathrm{pg} / \mathrm{ml})(\mathrm{P}<0.05)$ (Table III).

Analysis of correlation between changes in intestinal flora and serum IL-10 and IL-17 in the patient group. The Pearson's correlation analysis shows that the $\mathrm{B} / \mathrm{E}$ value representing the changes in intestinal flora in the patient group were negatively correlated to serum IL-10 ( $\mathrm{r}=-0.546, \mathrm{P}<0.05)$, and also negatively correlated with serum IL-17 ( $\mathrm{r}=-0.535, \mathrm{P}<0.05)$ (Figs. 3 and 4).

\section{Discussion}

Intestinal flora in the human body comprise a complex micro-ecosystem composed of probiotics and pathogens. In this micro-ecosystem, the beneficial bacteria and pathogenic bacteria combine in accordance to a certain proportion, and they are extremely important in digestion and absorption within the human body via mutual regulation (7-9). Research shows that (10) the development and progression of liver diseases are closely related to the intestinal microbiology. It has also been reported that $(11,12)$ intestinal probiotics can reduce oxidative stress and inflammatory injury in the liver, which plays a very important roles in the prevention of nonalcoholic fatty liver diseases. The B/E value can generally be used to assess the changes in intestinal flora. This study shows that the number of beneficial bacteria, such as Bifidobacterium and Lactobacillus, in the patient group was significantly lower than in the control group $(\mathrm{P}<0.05)$. On the other hand, the number of pathogenic bacteria, such as Enterobacteriaceae and Enterococcus, in the patient group was significantly higher than that in control group $(\mathrm{P}<0.05)$. The $\mathrm{B} / \mathrm{E}$ value in
Table III. Comparison of serum IL-10 and IL-17 levels between the two groups (mean \pm standard deviation, $\mathrm{pg} / \mathrm{ml}$ ).

\begin{tabular}{lccc}
\hline Groups & $\mathrm{n}$ & $\mathrm{IL}-10$ & $\mathrm{IL}-17$ \\
\hline Patient & 90 & $1.17 \pm 0.15$ & $0.96 \pm 0.11$ \\
Control & 80 & $0.32 \pm 0.04$ & $0.28 \pm 0.01$ \\
t-test & & 8.042 & 9.735 \\
P-value & & $<0.05$ & $<0.05$ \\
\hline
\end{tabular}

IL, interleukin.

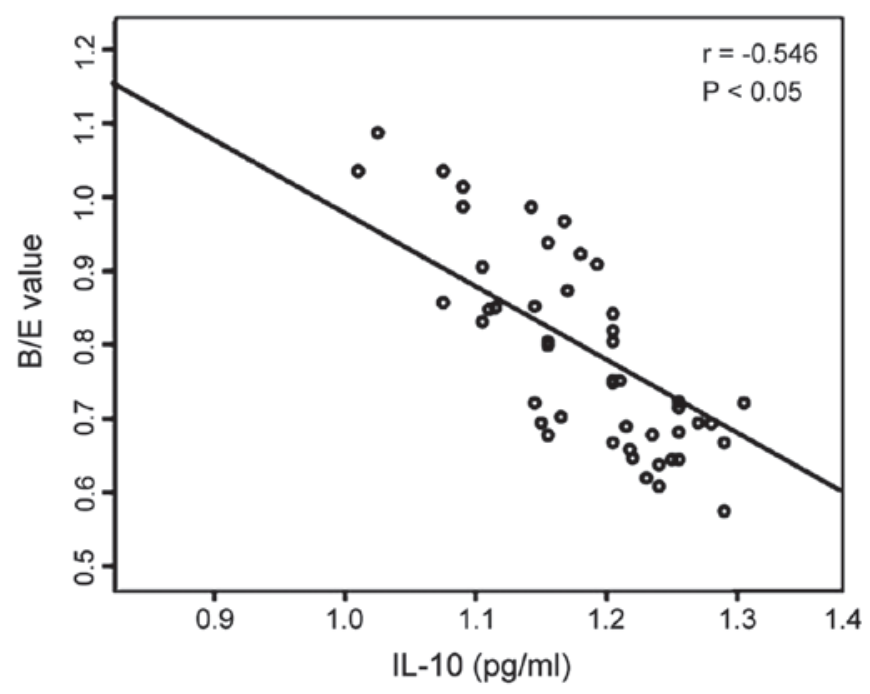

Figure 3. Correlation between B/E value and serum IL-10. B/E, Bifidobacterium to Enterobacter; IL, interleukin.

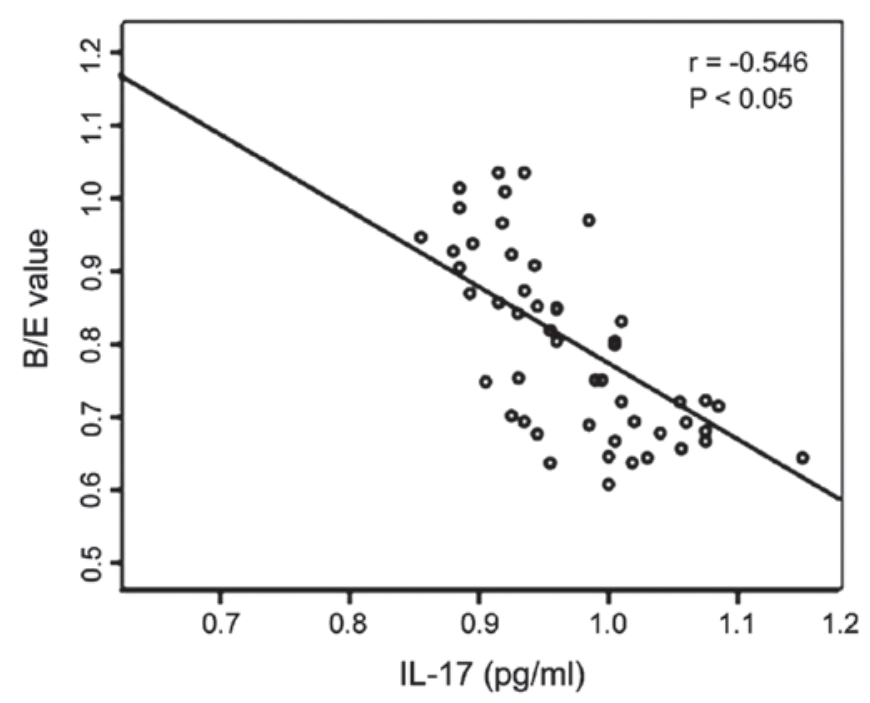

Figure 4. Correlation between $\mathrm{B} / \mathrm{E}$ value and serum IL-17. B/E, Bifidobacterium to Enterobacter; IL, interleukin.

the patient group was significantly lower than that in control group $(\mathrm{P}<0.05)$, which suggests that the imbalance of intestinal flora exists in nonalcoholic steatohepatitis, and leads to the injury of intestinal colonization resistance. 
Studies have suggested that $(5,13)$ the pathogenesis of nonalcoholic fatty liver disease may be associated with oxidative stress, inflammatory response and other factors. Oxidative stress generally promotes the inflammatory response and releases a variety of inflammatory factors, such as IL-10 and IL-17 (14-17). This study demonstrates that the relative expression levels of IL-10 and IL-17 mRNA in the patient group were significantly higher than those in the control group $(\mathrm{P}<0.05)$. The serum IL-10 levels in patient group were $1.17 \pm 0.15 \mathrm{pg} / \mathrm{ml}$, which was significantly higher than that in the control group at $0.32 \pm 0.04 \mathrm{pg} / \mathrm{ml}(\mathrm{P}<0.05)$. Furthermore, the serum IL-17 levels in the patient group was $0.96 \pm 0.11 \mathrm{pg} / \mathrm{ml}$, which was significantly higher than that in the control group $(0.28 \pm 0.01 \mathrm{pg} / \mathrm{ml})$ $(\mathrm{P}<0.05)$, which suggests that the increased IL-10 and IL-17 levels are closely related to the development and progression of nonalcoholic steatohepatitis and can reflect the severity of nonalcoholic steatohepatitis.

Due to the close correlation between the changes in intestinal flora, inflammatory factors and the incidence of nonalcoholic steatohepatitis, the $\mathrm{B} / \mathrm{E}$ value was used to reflect the changes in the intestinal flora, and the correlation analysis was performed for IL-10 and IL-17 in order to provide a related basis for the pathogenesis of nonalcoholic steatohepatitis. The results of this study show that the $\mathrm{B} / \mathrm{E}$ value in the patient group was negatively correlated with serum IL-10 $(\mathrm{r}=-0.546, \mathrm{P}<0.05)$, and also negatively correlated with serum IL-17 $(r=-0.535, P<0.05)$, which suggests that the imbalance of intestinal flora is related to the damage extent of intestinal colonization resistance and changes in the levels of inflammatory factors, IL-10 and IL-17. It is speculated that the hepatic pathological changes, the imbalance of intestinal flora and the release of inflammatory factors may occur in nonalcoholic steatohepatitis, thus promoting liver injury in the human body $(3,18)$.

In conclusion, IL-10 and IL-17 are highly expressed in the peripheral blood of patients with nonalcoholic steatohepatitis compared to healthy people. The changes in intestinal flora in patients with nonalcoholic steatohepatitis are closely related to the changes in serum IL-10 and IL-17 levels, and they interact and actively participate in the development and progression of nonalcoholic steatohepatitis.

\section{References}

1. Zhu L, Baker SS, Gill C, Liu W, Alkhouri R, Baker RD and Gill SR: Characterization of gut microbiomes in nonalcoholic steatohepatitis (NASH) patients: A connection between endogenous alcohol and NASH. Hepatology 57: 601-609, 2013.

2. Ilan Y: Leaky gut and the liver: A role for bacterial translocation in nonalcoholic steatohepatitis. World J Gastroenterol 18: 2609-2618, 2012.

3. Wu WC, Zhao W and Li S: Small intestinal bacteria overgrowth decreases small intestinal motility in the NASH rats. World J Gastroenterol 14: 313-317, 2008.
4. Tsujimoto T, Kawaratani H, Kitazawa T, Uemura M and Fukui H: Innate immune reactivity of the ileum-liver axis in nonalcoholic steatohepatitis. Dig Dis Sci 57: 1144-1151, 2012.

5. Safadi R, Konikoff FM, Mahamid M, Zelber-Sagi S, Halpern M, Gilat T, Oren R, Safadi R, Konikoff FM, Hershkovitz A, et al; FLORA Group: The fatty acid-bile acid conjugate Aramchol reduces liver fat content in patients with nonalcoholic fatty liver disease. Clin Gastroenterol Hepatol 12: 2085-91.e1, 2014.

6. Santos LF, Hernández G, Puerta AV, Beltrán O, Botero RC and Mejía G : Non alcoholic fatty liver disease: The new millennium pandemia. Rev Col Gastroenterol 25: 380-398, 2010.

7. Schartum-Hansen H, Pedersen ER, Svingen GF, Ueland PM, Seifert R, Ebbing M, Strand E, Bleie $\varnothing$ and Nygård O: Plasma choline, smoking, and long-term prognosis in patients with stable angina pectoris. Eur J Prev Cardiol 22: 606-614, 2015.

8. Søndergaard B, Olsson J, Ohlson K, Svensson U, Bytzer P and Ekesbo R: Effects of probiotic fermented milk on symptoms and intestinal flora in patients with irritable bowel syndrome: A randomized, placebo-controlled trial. Scand J Gastroenterol 46: 663-672, 2011.

9. Armand-Lefèvre L, Angebault C, Barbier F, Hamelet E, Defrance G, Ruppé E, Bronchard R, Lepeule R, Lucet JC, El Mniai A, et al: Emergence of imipenem-resistant gram-negative bacilli in intestinal flora of intensive care patients. Antimicrob Agents Chemother 57: 1488-1495, 2013.

10. Steensels D, Slabbaert K, De Wever L, Vermeersch P, Van Poppel H and Verhaegen J: Fluoroquinolone-resistant $E$. coli in intestinal flora of patients undergoing transrectal ultrasound-guided prostate biopsy - should we reassess our practices for antibiotic prophylaxis? Clin Microbiol Infect 18: 575-581, 2012.

11. Hotten P, Marotta F, Naito Y, Minelli E, Helmy A, Lighthouse J, Fuji $\mathrm{H}$ and Fesce E: Effects of probiotics, lactitol and rifaximin on intestinal flora and fecal excretion of organic acids in cirrhotic patients. Chin J Dig Dis 4: 13-18, 2003.

12. Xu RY, Wan YP, Fang QY, Lu W and Cai W: Supplementation with probiotics modifies gut flora and attenuates liver fat accumulation in rat nonalcoholic fatty liver disease model. J Clin Biochem Nutr 50: 72-77, 2012.

13. Omura Y, Kitamoto M, Hyogo H, Yamanoue T, Tada Y, Boku N, Nishisaka T, Miyauchi M, Takata T and Chayama K: Morbidly obese patient with non-alcoholic steatohepatitis-related cirrhosis who died from sepsis caused by dental infection of Porphyromonas gingivalis: A case report. Hepatol Res 46: E210-E215, 2016.

14. Habior A: Nonalcoholic fatty liver disease and obesity. Nutr Clin Pract 22: 1-10, 2013 (In Polish).

15. El-Bassiouni NE, El Messery LO, Zayed RA, Metwally OB, Zahran MY, Mahmoud OM, Ibrahim RA and El Bassiouny AE: Tissue factor expression on blood monocytes in patients with hepatitis $C$ virus-induced chronic liver disease. Comp Clin Pathol 23: 1159-1166, 2014.

16. Tarantino G: Nutrition: A promising route for prevention and management of obesity-related nonalcoholic fatty liver disease. Horm Mol Biol Clin Investig 20: 39-41, 2014

17. Mcavoy NC, Ferguson JW, Campbell IW and Hayes PC: Review: Non-alcoholic fatty liver disease: natural history, pathogenesis and treatment. Br J Diabetes Vasc Dis 6: 251-260, 2006.

18. Kwak DS, Jun DW, Seo JG, Chung WS, Park SE, Lee KN, Khalid-Saeed W, Lee HL, Lee OY, Yoon BC, et al: Short-term probiotic therapy alleviates small intestinal bacterial overgrowth, but does not improve intestinal permeability in chronic liver disease. Eur J Gastroenterol Hepatol 26: 1353-1359, 2014. International (CC BY-NC-ND 4.0) License. 